\title{
Timed Up and Go test: a simple test gives important information in elderly
}

Teste Timed Up and Go: um teste simples que nos fornece importantes informações em idosos

\author{
Sonia Maria Dozzi Brucki
}

Universidade de São Paulo, Grupo de Neurologia Cognitiva e Comportamental, Sao Paulo SP, Brazil.

Correspondence:

Sonia Maria Dozzi Brucki; Rua Rio Grande, 180; 04018-000 São Paulo SP, Brasil; E-mail: sbrucki@uol.com.br

Conflict of interest:

There is no conflict of interest to declare.

Received 11 February 2015 Accepted 18 February 2015

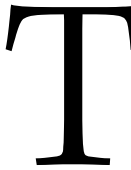

he Timed Up and Go test (TUG) is a largely used test to measure gait, motor speed, frailty and physical function in elderly ${ }^{1,2}$, besides as a predictor of risk of falls ${ }^{3}$. It has been considered a predictor of activities of daily living in community cohorts $^{4,5}$.

In another studies TUG test has been associated with cognitive test to increment difficulty in dual-task paradigms, with an increasing rate of falls $s^{6}$ and an impaired performance among subjects with cognitive impairment ${ }^{7}$. In the study of Mirelman et al. authors have tried to assess TUG in older individuals without dementia and with mild cognitive impairment; they observed that time of completion of TUG was not different, but the quality was, showing motor-cognitive interactions ${ }^{8}$.

Studies with Parkinson's disease patients have demonstrated TUG is associated with cognitive impairment ${ }^{9,10}$.

Many authors have used TUG with dual task (TUG-DT) that has been demonstrated as a good measure of gait disorders among elders; the tasks can be motor or cognitive. In the study of Christofoletti et al. dual task had a great influence on performance in patients with Alzheimer's disease and Parkinson's disease; it is important information for care of patients and their activities of daily living, which include dual tasks ${ }^{11}$.

The manuscript entitled Age and education influence the performance of elderly women on the dual-task Timed Up and Go test published in this current number investigated the influences of age, education and physical activity among 92 elderly women from community, on TUG dual task ${ }^{12}$. Although TUG has reference time values well established, there is no normative data investigating TUG-DT and education in Brazil. This manuscript gives us some data related to this important topic. Cognitive reserve could be a theoretical background since education is a surrogate for this concept and is associated with better health and physical conditions and, consequently better performance in TUG-DT. Two age groups (69 to 74 years; 75 to 79 years) and two education groups (3-4 years and 8 years) were analyzed; and both were grouped as sedentary or active. The oldest group had higher dual task cost (percentage of spent time comparing TUG and TUG-DT); higher education was associated with better performance in all measures. The number of falls over the last six months was reported more times by the younger group. An unexpected finding was sedentary and active women performed equally on tasks.

This sample has showed a greater average time than other studies described in a recent meta-analysis ${ }^{13}$, but possibly methodology was different. This manuscript was well designed and the results could be used as a parameter of normality in different age and educational groups in elderly women. 
1. Bennell K, Dobson F, Hinman R. Measures of physical performance assessments: Self-Paced Walk Test (SPWT), Stair Climb Test (SCT), Six-Minute Walk Test (6MWT), Chair Stand Test (CST), Timed Up and Go (TUG), Sock Test, Lift and Carry Test (LCT), and Car Task. Arthritis Care Res. 2011;63(suppl S11): S350-70. http://www.dx.doi. org/10.1002/acr.20538

2. Kubicki A. Functional assessment in older adults: should we use timed up and go or gait speed test? Neurosci Lett. 2014;577:89-94. http://www.dx.doi.org/10.1016/j.neulet.2014.06.014

3. Barry E, Galvin R, Keogh C, Horgan F, Fahey T. Is the Timed Up and Go test a useful predictor of risk of falls in community dwelling older adults: a systematic review and meta-analysis. BMC Geriatr. 2014;14:14. http://www.dx.doi.org/10.1186/1471-2318-14-14.

4. Sakamoto R, Okumiya K, Ishine M, Wada T, Fujisawa M, Imai $\mathrm{H}$ et al. Predictors of difficulty in carrying out basic activities of daily living among the old-old: a 2-year community-based cohort study. Geriatr Gerontol Int. Forthcoming 2015. http://www.dx.doi.org/ 10.1111/ggi.12462

5. Donoghue OA, Savva GM, Cronin H, Kenny RA, Horgan NF. Using timed up and go and usual gait speed to predict incident disability in daily activities among community-dwelling adults aged 65 and older. Arch Phys Med Rehabil. 2014;95(10):1954-61. http://www.dx.doi.org/ 10.1016/j.apmr.2014.06.008

6. Ansai JH, Aurichio TR, Rebelatto JR. Relationship between balance and dual task walking in the very elderly. Geriatr Gerontol Int. Forthcoming 2015. http://www.dx.doi.org/10.1111/ggi.12438

7. Tseng BY, Cullum CM, Zhang R. Older adults with amnestic mild cognitive impairment exhibit exacerbated gait slowing under dual-task challenges. Curr Alzheimer Res. 2014;11:494-500. http://www.dx.doi.org/10.2174/1567205011666140505110828

8. Mirelman A, Weiss A, Buchman AS, Bennett DA, Giladi N, Hausdorff JM. Association between performance on Timed Up and Go subtasks and mild cognitive impairment: further insights into the links between cognitive and motor function. J Am Geriatr Soc. 2014;62(4):673-8. http://www.dx.doi.org/10.1111/jgs.12734

9. Stegemöller EL, Nocera J, Malaty I, Shelley M, Okun MS, Hass CJ. Timed up and go, cognitive, and quality-of-life correlates in Parkinson's disease. Arch Phys Med Rehabil. 2014;95(4):649-55. http://www.dx.doi.org/10.1016/j.apmr.2013.10.031

10. Herman T, Weiss A, Brozgol M, Giladi N, Hausdorff JM. Identifying axial and cognitive correlates in patients with Parkinson's disease motor subtype using the instrumented Timed Up and Go. Exp Brain Res. 2014;232(2):713-21. http://www.dx.doi.org/10.1007/s00221-0133778-8

11. Christofoletti G, Andrade LP, Beinotti F, Borges G. Cognition and dualtask performance in older adults with Parkinson's disease and Alzheimer's disease. Int J Gen Med. 2014;7:383-8. http://www.dx.doi. org/10.2147/IJGM.S65803

12. Gomes GC, Teixeira-Salmela LF, Fonseca BF, de Freitas FAS, Fonseca MLM, Pacheco BD et al. Age and education influence the performance of elderly women on the dual-task Timed Up and Go Test. Arq Neuropsiquiatr 73(3):187-93. http://www.dx.doi.org/10.1590/0004282X20140233

13. Bohanon RW. Reference values for the timed up and go test: a descriptive meta-analysis. J Geriatr Phys Ther. 2006;29(2):64-8. http://dx.doi.org/10.1519/00139143-200608000-00004 